\title{
O SABER GEOGRÁFICO E SEU DESENVOLVIMENTO NA ESCOLA PÚBLICA: reflexão/prática.
}

\author{
Marluce Silva Sousa ${ }^{1}$ \\ Dimas Moraes Peixinho ${ }^{2}$
}

\section{Resumo}

O texto apresenta considerações sobre o desenvolvimento do ensino de Geografia com base nas experiências de estágio de fim de curso da Licenciatura em Geografia. Primeiramente, é abordada a importância e os tipos de saber geográfico. Depois, trata-se da distância entre o saber cientificamente produzido e aquele ensinado nas escolas e das dificuldades de aprendizagem do saber geográfico e suas causas. É apontada, como proposta, que se considere e aperfeiçoe o saber geográfico que os alunos levam para a escola.

Palavras-chave: Geografia. Conhecimento geográfico. Ensino de Geografia.

\begin{abstract}
This text presents considerations about the development of geography teaching on the basis of the experiences obtained in the final training period of the graduation in geography. At first, we analyze the importance and the types of geographic knowledge. Later, we discuss the distance between knowledge scientifically produced and that one taught at school, as well as the difficulties to learn geographic knowledge and their causes. We suggest that we consider and improve the geographic knowledge that students take to school.
\end{abstract}

Key words: Geography; Geographic knowledge; Geography Teaching.

\section{A importância do saber geográfico}

Embora o conhecimento geográfico exista desde os primeiros tempos do homem e tenha recebido especial contribuição daquele conhecimento produzido e acumulado por viajantes e colecionadores ao longo da história, a sistematização da Geografia é recente e emerge em função da necessidade de conhecimento territorial na Alemanha e na França do século XIX.

Este histórico de seu surgimento (em função de necessidade geopolítica) justifica a afirmação de Yves Lacoste, de que a Geografia serve, em primeiro lugar, para fazer a guerra.

Por trás dessa afirmação há ainda outro ponto que destacamos: o caráter pragmático acerca da ciência moderna, diferentemente, por exemplo, do caráter do conhecimento elaborado na Grécia antiga. E é por isso que, ao pretender abordar a

\footnotetext{
${ }^{1}$ Mestranda do Instituto de Estudos Sócio-Ambientais da Universidade Federal de Goiás. E-mail: mss geo@hotmail.com. R. Riachuelo n.1530, Setor Samuel Graham.

${ }^{2}$ Professor do Campus Avançado de Jataí. dpeixinho@bol.com.br.
} 
importância do saber geográfico, geralmente é necessário iniciar a argumentação com a indagação, para que serve a Geografia?

E, de fato, este é o título de um artigo de Antônio Teixeira Neto: "Para que serve a Geografia?" Interrogativa a que ele tenta responder:

(...) a geografia serve para situar o homem em suas múltiplas relações de interdependência com seu meio ambiente na terra que lhe dá um sentimento para a vida. (...) a geografia dá ao homem a medida que o tornará capaz de aplicar de modo libertador os conhecimentos teóricos de que ele dispõe (TEIXEIRA NETO, 2003, p. 1)

Neste contexto, ele aponta que o papel do geógrafo é

(...) trabalhar a um só tempo às partes e o todo contribuindo para o entendimento de que natureza e sociedade constituem uma unidade indissolúvel e que no campo do conhecimento humano, se ele não é o único, é seguramente o mais privilegiado para fazer as análises espaciais complexas que resultam da interação entre os homens e o seu ambiente natural, a terra (TEIXEIRA NETO, 2003, p. 1)

Concordando com esta idéia, Valter Casseti (1991) diz que a Geografia permite a aproximação do homem com a natureza e o geógrafo tem condições efetivas de dominar a amplitude interdependente do complexo sociedade-natureza.

Como contribuição prática, o saber geográfico contribui para subsídio a políticas de planejamento ambiental, regional e urbano, além de aplicações específicas, em relação ao clima e pedologia.

Já a contribuição da Geografia para o ensino fundamental e médio ocorre no sentido de desenvolver a capacidade de observar, analisar, interpretar e pensar criticamente a realidade tendo em vista a sua transformação. A compreensão da realidade, ou seja, do espaço produzido e das relações entre os homens e a natureza, passa pela compreensão das relações sociais de produção deste espaço. Além disso, a Geografia busca a compreensão das diferenças espaciais e a orientação, localização e representação dos dados espaciais. Dessa maneira, o ensino de Geografia atualmente tem uma fundamental importância no currículo escolar (OLIVEIRA, 1991).

\section{Os diferentes "conhecimentos geográficos"}

Segundo Peixinho (2003, p. 1)

[...] o conhecimento geográfico, enquanto conhecimento prático, nos remeterá para os primeiros tempos do homem. Pois, o homem, na sua luta cotidiana para promover a 
sua subsistência sempre necessitou estabelecer uma relação com a natureza buscando uma organização espacial. Se nos primeiros tempos essa organização era simples, baseada na coleta de frutos, raízes e na caça aos animais para satisfazer suas necessidades de alimentação e abrigo, essa organização espacial vai se tornando mais complexa e exigindo cada vez mais uma reorganização espacial, o que significa produzir novas formas de apropriação da natureza.

À medida que o conhecimento geográfico se sistematizou, adquiriu status de ciência, foi se distanciando do saber geográfico popular, do conhecimento do senso comum. Dessa maneira, com base em textos consultados e, sem pretensão de avançar, mas apenas destacar alguns pontos, pode-se dizer que há um conhecimento cientificamente produzido pela Geografia e outro conhecimento geográfico sendo ensinado nas escolas (a "geografia dos professores", para Yves Lacoste) e outro ainda, aquele pré-escolar, que brota da vivência prática e social dos alunos.

Em relação aos dois primeiros, Cavalcanti (1998, p. 9) coloca:

A relação entre uma ciência e a matéria de ensino é complexa; ambas formam uma unidade, mas não são idênticas. A ciência geográfica constitui-se de teorias, conceitos e métodos referentes à problemática de seu objeto investigação. A matéria de ensino Geografia corresponde ao conjunto de saberes dessa ciência, e de outras que não têm lugar no ensino fundamental e médio, como astronomia, economia, geologia, convertidos em conteúdos escolares a partir de uma seleção e de uma organização daqueles conhecimentos e procedimentos tipos como necessários à educação geral $[\ldots]$.

Para Ariovaldo Umbelino de Oliveira, a Geografia que se ensina, tanto nas escolas no fundamental e médio e até mesmo no nível superior, não tem, na maioria das vezes, quase mais nada a ver com a Geografia que se produz nas universidades, em nível da pesquisa.

Para o autor, a questão passa pela prática do professor:

\begin{abstract}
Nesse processo o professor foi perdendo ou, então, nem teve a oportunidade de formar sua condição de produtor de conhecimentos. Ele se tornou ou foi transformado em um mero repetidor dos conteúdos dos livros didáticos. As editoras chegaram inclusive a publicar o livro do professor, uma espécie de cartilha, na suposição de lhe facilitar o trabalho (OLIVEIRA, 1991, p.138).
\end{abstract}

Portanto, a questão da prática de ensino em Geografia vai além da teoria geográfica produzida nas universidades que, em geral, chega tardiamente, e de forma defasada, às escolas. Ao chegar à escola, os conteúdos são, ainda, selecionados pelo professor, ao qual cabe: 
[...] a tarefa de ensinar os conceitos elementares da geografia [...] E a transmissão/formação desses conceitos passa necessariamente pela questão ideológica, da ideologia de classes que ele, professor professa. Esta ideologia é que dá parâmetro para a definição e escolha da geografia que ele ensina [...] (OLIVEIRA, 1991, p. 143).

Já é conhecida toda a problemática educacional que o país vem passando, especialmente no que se refere aos professores: os salários são baixos forçando o professor a ter uma jornada de trabalho incompatível com a docência, falta de formação continuada e péssimas condições de trabalho. Mas consciência da sua condição de docente, definição de uma ideologia (como acima aponta Ariovaldo Oliveira), definição dos objetivos, seleção do conteúdo e a escolha dos métodos para a prática em sala de aula remetem, sobretudo, à formação do professor de Geografia. Conforme nos apresenta Genylton O. Rego da Rocha, o ensino da Geografia (e do ensino secundário, em geral), até 1930, quando então foram criadas as licenciaturas em Geografia era deixado a cargo dos médicos sem clínica, dos bacharéis sem causa, dos engenheiros que falharam. Isso não mudou muito com o passar dos anos. Atualmente a Lei de Diretrizes e Bases da Educação Brasileira dá sustentação ao aligeiramento das licenciaturas, o que, somado à crescente privatização e mercantilização do ensino superior, resulta numa perspectiva cada vez mais pessimista quanto à qualidade da formação de professores.

[...] o resultado de tudo isso foi uma qualidade de ensino que deixa muito a desejar. Alunos e professores têm sido uma espécie de vítimas desse processo. A geografia que se ensina e se aprende não os motiva mais e, seguramente, está muito longe das suas reais necessidades [...] (OLIVEIRA, 1991, p.138).

Dessa maneira, a Geografia ensinada atualmente passa por problemas sérios, constatados, quase com unanimidade, nos estágios na disciplina de Prática de Ensino em Geografia. As observações realizados no estágio do $4^{\circ}$ ano de Licenciatura em Geografia, no ano de 2004, permitiram verificar que os professores parecem estar tão desanimados quanto os alunos: não participam da construção do espaço geográfico da escola, selecionam os conteúdos conforme sua maior ou menor habilidade com os mesmos, não se preocupam com formação continuada e com a atualização da Geografia científica e, em geral, não se comprometem com a aprendizagem, mas sim com o cumprimento do programa e com a seqüência do livro didático. Nota-se, ainda, que nos eventos produzidos pelo Departamento de Geografia a participação dos professores do ensino fundamental e médio é reduzida. O livro didático, por sua vez, em razão de ser o principal, senão o único recurso didático, deveria ser 
de qualidade e ter um uso voltado para a realidade dos alunos. Quanto aos alunos, estes estão desmotivados, indisciplinados e não alcançam os objetivos do ensino de Geografia, isto é, a aprendizagem não é satisfatória, mesmo que os professores acreditem que ensinaram. Por isso, é razoável a afirmação de Yves Lacoste (1997, p. 38):

\begin{abstract}
A geografia escolar que foi imposta a todos no fim do século XIX e cujo modelo continua a ser reproduzido ainda hoje, quaisquer que possam ter sido os progressos na produção de idéias científicas, encontra-se totalmente alheada de toda a prática. De todas as diciplinas na escola (...), a geografia é, ainda hoje, a única que surge como um saber sem a mínima aplicação prática fora do sistema de ensino.
\end{abstract}

A constatação da inaplicação prática da Geografia é preocupante, desanimadora e, talvez, por isso, haja tanta desmotivação em relação à disciplina. Enquanto, teoricamente tanto se repete a necessidade da interação físico-humana, a preocupação ambiental, os objetivos de conscientizar e, principalmente de tornar o aluno "crítico" (note-se a insistência dessa palavra nos objetivos de ensino) a prática de ensino em Geografia continua não estabelecendo as mínimas relações sequer entre os elementos da natureza, divididos em geral, em relevo, hidrografia, clima e vegetação, quanto mais desses com os elementos humanos. A análise ambiental está presa ao livro didático que, amassado e rabiscado, poucas vezes é aberto pelo aluno, o qual está mais atento ao chiclete que masca e que logo a seguir jogará no chão ou na carteira do colega. Os exercícios, geralmente repetitivos, não proporcionam aos alunos analisar o conteúdo. $\mathrm{O}$ estudo do espaço socialmente produzido não chega ao aluno, que o estuda fragmentando e, assim, não se percebe enquanto sujeito ativo e transformador do mesmo. Por isso, aluno consciente e crítico continua sendo a utopia presente apenas no planejamento de ensino.

Quando questionados ${ }^{3}$ sobre o gosto pela disciplina, os alunos respondem afirmativamente. A maior parte gosta de Geografia porque aprende mais sobre os "estados", mas nenhum deles consegue responder o que é estado. Em geral, eles não sabem também para que lhes servirá o estudo de Geografia e não conseguem aprender o que os professores ensinam

$\mathrm{Na}$ tentativa de levantar, em parte e despretensiosamente, algum caminho mais otimista para o ensino de Geografia, arriscamo-nos a dizer, além, é claro, de buscar melhorias estruturais na educação do país, que é preciso que a prática escolar reconheça o significado dos saberes que são construídos fora da estrutura formal da escola, na prática cotidiana dos

\footnotetext{
${ }^{3}$ Entrevistas realizadas com alunos da $6^{\mathrm{a}}$ série de uma escola municipal de Jataí, com idade entre 11 e 14 anos.
} 
alunos. Márcia Spyer Resende, em pesquisas com alunos adultos das séries iniciais, demonstra a existência desse conhecimento e seu estreito vínculo com o lugar do aluno no processo social de produção.

Tratamos da importância do saber geográfico, do questionável conhecimento geográfico ensinado e podemos agora partir para a aprendizagem dos alunos a respeito do conhecimento geográfico. Na maioria das vezes, os alunos não dão importância a disciplina de Geografia, não adquirem os conceitos geográficos significativos para a sua atuação social e sequer imaginam para que serve a Geografia. Em síntese: evidenciada a importância da Geografia, o seu papel na formação de um aluno consciente e participativo, conhecidas as dificuldades no ensino, nota-se que, na prática, os alunos não estão aprendendo Geografia.

Concordando com Resende (1989), essa questão passa pelo método de ensino, que, em geral nega o espaço histórico do aluno, marginaliza o próprio aluno como sujeito do processo de conhecimento e transforma-o em objeto desse processo. $\mathrm{O}$ aluno é considerado um ser neutro, sem cultura, sem história, receptáculo de informações, entidade alheia ao momento histórico e aos espaços geográficos determinados.

A conseqüência desse processo não podia ser outra: o aluno não se percebe como participante do espaço geográfico que estuda. Se o espaço não é encarado como algo em que o homem (aluno) está inserido, natureza que ele próprio ajuda a moldar, a verdade geográfica do indivíduo se perde e a Geografia torna-se alheia a ele (RESENDE, 1989).

Pesquisando sobre o saber geográfico de alunos da classe trabalhadora, Resende $(1989$, p. 87) diz o seguinte:

\begin{abstract}
Para essas pessoas a geografia é, acima de tudo, esse espaço real, que pode não valer, num primeiro momento - sabemos nós-, como verdade científica, pois só muito raramente transcende o particular para chegar ao geral. Mas nem por isso é menos verdadeira, já que é riquíssima porque intensa e pessoal percepção do espaço resultante de uma determinada vivência, cujas normas se devem à divisão social do trabalho. Tal vivência pode ser, por isso mesmo, tão necessária à ciência geográfica quanto o que mais seja, pelo seu caráter de saber não- teorizado, não- trabalhado pelas múltiplas linguagens de cultura, pelo seu caráter, enfim, de saber originário produzido pela ação do homem sobre a natureza, mas que é, via de regra, deliberada ou inadvertidamente ignorada pela escola, isto quando não simplesmente considerado como um obstáculo ao verdadeiro saber.
\end{abstract}

Há um choque, então, entre a Geografia ensinada e esse saber geográfico que o aluno possui. Os alunos, especialmente aqueles de origem camponesa, não sabem os nomes dos códigos formais que define o clima, ou os nomes científicos dos solos, mas sabem em que época se planta, os solos mais produtivos, sabem escolher as melhores sementes, etc. Não 
sabem os conceitos referentes às relações sociais de produção, mas sabem, por exemplo, que há uma hierarquia na organização da sua família.

Evidencia-se, assim, a importância do uso de um método adequado para chegar aos objetivos almejados. Objetivos de ensino sócio-políticos e pedagógicos (gerais do ensino e específicos da escola) que devem orientar a seleção e organização dos conteúdos e alcançados por meio do método de ensino e não o contrário, como se tem verificado na prática: os conteúdos é que têm orientado o estabelecimento de objetivos, colocados apenas no papel, quando o professor chega a fazer um planejamento. Para isso, a formação, o interesse e o compromisso político, técnico e pedagógico do professor são essenciais.

Mas, voltando à questão do método, Cavalcanti (1998) faz menção à linha da Didática Crítico- social e às proposições de Vygotsky, segundo o qual o conhecimento escolar se constrói pelo confronto entre conceitos cotidianos e conceitos científicos. Se o professor tem a concepção de que a construção de conceitos geográficos é o instrumental para a compreensão do espaço, então ele tem que incluir o saber do aluno para a formação dos conceitos sócio. E é por isso que pontuamos o saber do aluno como um conhecimento importante para a construção da prática de ensino de Geografia eficiente. Como aponta Resende (1989, p.115):

\begin{abstract}
Ao contrário do que tantas vezes amamos acreditar, não se trata de um saber préescolar, nem tampouco de um obstáculo ao verdadeiro saber. É um saber como qualquer outro e, mais que isso, um saber que, se devidamente considerado, pode sem dúvida alguma facilitar o acesso desses alunos ao conhecimento científico da geografia - aquilo que denominamos neste trabalho espaço geográfico. Uma geografia que não apenas cumpra o papel de intrigar o aluno- e que não sabe ou não quer responder "como e porque as coisas chegou no pé que chegou", como afirma a aluna Rita- mas que, partindo da verdade do aluno, de seu saber real, de sua inquietação real, possa transcender-la, elevando esse saber real, de sua inquietação real, possa transcedela- la, elevando esse saber, sem saber, sem ignora-lo nem destruí-lo, ao patamar do rigor científico.
\end{abstract}

\title{
3- Considerações finais
}

Se as experiências adquiridas no estágio da Licenciatura, assim como os relatos na literatura consultada podem ser generalizados, parece que os alunos do ensino fundamental e médio das escolas públicas não vão à escola para aprender. Ainda menos aprender Geografia, que não lhes parece ter utilização nas vidas cotidianas.

Os mais jovens vão à escola porque lhes é imposto pelos pais, como relata um aluno da $6^{\text {a }}$ série: "Não gosto de vir para a escola. Prefiro ficar em casa assistindo televisão, mas minha mãe me manda vir". Pais trabalhadores induzem os filhos a irem para a escola 
porque não têm com quem deixá-los para ir ao trabalho, porque querem receber a "bolsa escola", porque todos fazem assim ou, raramente, porque acreditam que o conhecimento proporcionará aos seus filhos uma ascendência social futura.

A escola torna-se, então, para a criança e ainda mais para o adolescente, um ponto de encontro, de lazer, impossibilitadas que são, em geral, de ter acesso a outros locais-meio de cultura, lazer e, inclusive, alimentação.

Portanto, o desenvolvimento de um ensino de Geografia construtiva e eficiente, só acontecerá ao mesmo tempo em que forem resolvidos os problemas sociais e estruturais da educação no Brasil. Mas isso não deve ser justificativa para negligenciar os problemas por que passa o ensino de Geografia na atualidade e a busca de respostas positivas para a resolução destes problemas dentro mesmo da prática docente. É por isso que acredita-se que a melhoria do desenvolvimento do saber geográfico no ensino fundamental e médio requer um compromisso do profissional de Geografia e do reconhecimento de que os alunos têm, na prática, o seu saber geográfico e é preciso conscientizá-los disso e partir desses conhecimentos para mediar o ensino e alcançar os objetivos propostos.

De certa forma, a escola tem sido um lugar que explora pouco o saber extraescolar, com isso acaba por distanciar o saber científico do cotidiano dos alunos. Criando assim, um ambiente de desencontros entre as experiências do cotidiano dos alunos e saberes sistematizados pela ciência. Assim, é preciso que os professores se coloquem mais como mediadores entre esses saberes, dando sentido a ambos como integrantes de elaborações que se complementam.

\section{Referências bibliográficas}

CASSETI. Valter. Ambiente e Apropriação do Relevo. São Paulo: Contexto, 1991.

CAVALCANTI, Lana de Souza. Geografia, Escola e Construção de Conhecimentos. Campinas: Papirus, 1998.

LACOSTE, Yves. A Geografia serve antes de tudo para fazer a guerra. São Paulo: Edusp, 1997.

TEIXEIRA NETO, Antônio. Para que serve a Geografia? In: Jornal da Geografia. Jataí (GO) n.1, 2003.

OLIVEIRA, Ariovaldo Umbelino de. Educação e Ensino de Geografia na Realidade Brasileira. In: OLIVEIRA, Ariovaldo Umbelino de et al. (Orgs.) Para onde vai o Ensino de Geografia? 3. ed. São Paulo: Contexto, 1991. p. 135-144.

PEIXINHO, Dimas Moraes. Fazer Geografia, Ser Geógrafo. In: Jornal da Geografia. Jataí (GO) n.2, 2003. 
RESENDE, Márcia M. Spyer. O saber do aluno e o ensino de Geografia. In: VESENTINI, José William et al. (Org.) Geografia e Ensino - Textos Críticos. Campinas (SP): Papirus, 1989 , p. 83-116.

ROCHA, Genylton O. R. da. Uma Breve História da Formação do (a) Professor (a) de Geografia no Brasil. s.d., s.l.

VESENTINI, José William. Geografia Crítica e Ensino. In: OLIVEIRA, Ariovaldo Umbelino de et al. (Org.) Para onde vai o Ensino de Geografia? 3. ed. São Paulo: Contexto, 1991. p. 30-38. 